\section{Trajetórias acadêmicas: um es- tudo comparado da carreira acadêmica em Minas Gerais}

Glícia S. Gripp ${ }^{1}$

Bruno Moreti Testi

Resumo: Este artigo pretende discutir alguns resultados de uma pesquisa ampla sobre o Ensino Superior em Minas Gerais, que contou com financiamento do CNPq. Preocupamonos com a carreira acadêmica. As variáveis que levamos em consideração são as seguintes: área de conhecimento (disciplina), trajetória de formação, produtividade (média de publicações nos últimos dez anos) e a região (do estado) na qual a instituição está localizada. Utilizamos como fonte de dados os currículos Lattes dos professores de diversos tipos de instituições de Ensino Superior do estado de Minas Gerais e tentamos desenhar um modelo de carreira acadêmica a partir da agregação dos dados. Observamos alguns resultados semelhantes ao encontrado na literatura sociológica: parece haver uma correlação forte entre o tipo de instituição em que o professor atua e a sua trajetória acadêmica e produtividade. Observamos, também, que há diferenças significativas nas trajetórias acadêmicas relacionadas às áreas de atuação ou campos de conhecimento.

Palavras-chave: Ensino Superior, Carreira Acadêmica, Trajetórias Profissionais, Prática Acadêmica.

\section{Introdução}

$\mathrm{N}$

o amplo campo da sociologia do Ensino Superior, escolhemos estudar os professores. Dentro dessa, ainda, grande categoria, escolhemos o tema "profissão acadêmica". O que significa ser acadêmico no século XXI? Essa é a pergunta que Welch (2007) se coloca ao tratar do professorado e a mesma pergunta colocamos no início deste trabalho. Como se verá, não há uma resposta clara a essa questão. Podemos imaginar, graficamente, um contínuo de posições, que vai de um polo ocupado por uma elite do professorado do Ensino Superior brasileiro - que se concentra em poucas universidades, tem dedicação exclusiva, pouca carga horária de ensino, e está em contato com a elite do professorado de outros países, possuindo acesso a boas bibliotecas e aos periódicos científicos relevantes de sua área, equipamentos para pesquisa e alunos escolhidos através de um sistema de seleção rigorosa; e, além disso, possui, entre seus pares, especialistas renomados e de alta produtividade - até o outro
Recebido:

06.08.2011

Aprovado:

05.05.2012

1. Doutora em Ciências Humanas (UFOP)

E-mail:

gliciagripp@gmail. com

2. Graduado História (UFOP)

E-mail:

brunotesti@gmail. com 
polo, ocupado por professores das faculdades isoladas privadas de Ensino Superior de cidades pequenas do interior do país, aparecendo no campo acadêmico em décadas recentes, nas últimas expansões do Ensino Superior. Cada professor real se situaria em um ponto entre esses dois polos. A pesquisa versa sobre essa diversidade e tenta traçar "tipos ideais" que deem conta das diferenças entre as carreiras que são constituídas pelas atividades acadêmicas e que recebem o nome de "professor", comparativamente.

Ao iniciarmos a pesquisa, verificamos que havia outra variável que não poderíamos deixar de considerar: a disciplina. Essa variável parece ter uma influência muito forte entre a elite acadêmica e muito fraca entre os professores das faculdades isoladas privadas de Ensino Superior. Ela é importante também para pensarmos as relações entre esses professores no nível organizacional e a dinâmica institucional decorrente que afeta o ensino ministrado nos estabelecimentos. Assim, outra comparação se impõe à pesquisa: a comparação entre os "tipos ideais" construídos para as diversas áreas do conhecimento. Optamos por estudar as seguintes áreas: engenharia civil, matemática, filosofia e psicologia.

A pesquisa se concentra no estudo - com uma intenção exploratória e descritiva - das várias etapas da prática do professor do Ensino Superior: do recrutamento, da formação, até as atividades cotidianas.

\section{A classificação dos professores}

Há poucos estudos sociológicos sobre a profissão acadêmica no Brasil. Um dos mais relevantes e importantes é o de Simon Schwartzman e Elizabeth Balbachevsky (1997), que propõe a classificação dos professores universitários brasileiros em três grupos distintos, com graus diferentes de profissionalização, a saber:

a) Professores em tempo parcial, sem estabilidade, com baixa especialização acadêmica, com uma carga horária elevada de aulas e prestando serviços ao setor privado.

b) Professores com qualificação média, estáveis, de tempo integral, com grande envolvimento em atividades sindicais e produção científica relativamente pequena.

c) Professor mais qualificado, envolvido em pesquisa com financiamento próprio, com pouca participação sindical e grande envolvimento com associações acadêmicas no país e no exterior.

Para fazer o recorte desses grupos, ou seja, para classificar os professores, os autores utilizam os dados agregados do censo educacional. Essa classificação 
tem por base uma definição de profissão acadêmica: há uma profissionalização "ideal" e as outras categorias seriam efeitos da deficiência desse processo, apesar da afirmativa de que não seria realista esperar que todos os professores evoluam em uma mesma direção. Os autores afirmam:

O mais razoável é supor que a profissão acadêmica no sentido estrito vai continuar limitada a um setor pequeno e diferenciado, e examinar as alternativas de profissionalização que poderiam ser pensadas para os demais. A atual situação de "profissionalização imperfeita" acaba gerando um grande número de distorções e frustrações, que vão das tentativas frustradas de manter uma atividade de pesquisa que não se materializa ao insulamento a que, de fato, muitos dos professores universitários são levados, ao perderem os vínculos com as profissões de origem, sem conseguirem efetivamente se incorporarem à nova. O "proletariado acadêmico" formado pelos professores horistas do sistema privado tampouco tem perspectivas claras de profissionalização, e haveria que pensar se caberia, de fato, esperar que esta profissionalização se desse neste setor. (SCHWARTZMAN \& BALBACHEVSKY, 1997, p. 22).

Assim, as diferenças encontradas em dados agregados (macro) são relacionadas pelos autores ao processo de profissionalização, tal como descrito pela literatura sociológica. Levando esse estudo em consideração, em nossa pesquisa, invertemos a lógica de construção do modelo profissional. A partir da agregação de dados individuais, das trajetórias profissionais individuais, tentaremos obter um modelo de profissionalização.

Acrescentamos às nossas preocupações teóricas, os insights contidos na sociologia das profissões, especialmente nos trabalhos de Freidson (1986), que mostram que pesquisa e erudição não caracterizam acuradamente as atividades dos membros da ciência e da arte acadêmicas. Pesquisa ou erudição constituem apenas um de seus papéis. Na verdade, uma grande parcela dos membros de todas as disciplinas acadêmicas não faz qualquer contribuição à literatura da pesquisa ou da erudição depois de terem escrito suas dissertações obrigatórias. A maior parte dos membros das disciplinas científicas, e a proporção varia de uma disciplina a outra, caracteristicamente executa o papel de ensino, que é a forma pela qual eles ganham sua vida. A elite entre eles tem encargos leves de ensino, ou é dispensada inteiramente do ensino, mas os encargos didáticos são a base para a contabilidade do tempo e compensação financeira da maioria dos pesquisadores e eruditos. O ensino teria, para o autor, um papel crítico de sustentação da vida e esta seria a base para considerá-los como membros de 
uma profissão, servindo a uma clientela leiga. Essas questões indicadas por Freidson não contradizem os dados das pesquisas brasileiras, mas, ao contrário, acreditamos que os refina, ao mostrar que, na realidade, há uma carreira acadêmica com perfis diferenciados.

Para analisarmos as distinções entre tipos de profissionais acadêmicos, em termos metodológicos, optamos por utilizar a noção de trajetória, a partir da ideia de que, desde que os indivíduos são os agentes sociais, o nível micro é um foco da análise. Assim, analisamos os currículos individualmente e depois agregamos os dados para verificar a possibilidade de existência de padrões. Pretendemos tomar uma perspectiva mais ampla sobre padrões de "trajetórias" de curso de vida profissional. Nosso objetivo é a identificação de padrões em trajetórias, ou de "equivalência sequencial", indicando que trabalharemos uma "análise sequencial". Procuraremos desvelar padrões nos dados para identificar o que os produz.

\section{Socialização e trajetória profissional}

\subsection{A socialização}

Em relação à socialização na profissão, observamos, a partir de nossos dados, o padrão seguinte:

a) Nas instituições privadas, de graduação, sem programas de pós-graduação, temos em torno de $30 \%$, para todas as áreas, de professores graduados em instituições públicas. O que demonstra que essas instituições reproduzem os seus quadros.

b) Nas instituições privadas, a qualificação dos professores é ainda baixa: a maioria, em todas as áreas, possui apenas graduação e especialização.

c) As universidades sem pós-graduação embora com resultados melhores, possuem também um número mais elevado de professores graduados em instituições privadas.

d) As universidades sem pós-graduação têm o corpo docente ainda com baixa qualificação, em comparação com as outras universidades.

\subsection{Trajetória profissional}

Denominamos de trajetória profissional o caminho seguido pelo professor em 
sua formação e consideramos os seguintes indicadores para traçar as trajetórias: tempo entre o término da graduação e início do mestrado, o tipo de emprego anterior à entrada na carreira acadêmica e o momento em que o professor iniciou a carreira acadêmica. Vejamos os dados para cada um dos cursos.

\section{a) Engenharia civil}

No estudo sobre a trajetória profissional dos professores, observamos que o tempo entre o término da graduação e o início do mestrado é muito superior para os professores das faculdades privadas (7,2 anos, em média) e das universidades sem programas de pós-graduação (6,9 anos). Há uma grande porcentagem de professores bolsistas de produtividade e de professores da UFMG que começaram sua trajetória profissional em empresas públicas ou privadas da área da engenharia, 59,2\% para o primeiro grupo e 48,3\% para o segundo. Isso não acontece com os outros grupos, que iniciaram a carreira profissional, em sua maioria, na docência do Ensino Superior. A maioria dos professores das instituições privadas iniciou a sua trajetória acadêmica após a graduação (69\%). O mesmo ocorre com os professores das universidades sem pós $(57,9 \%)$. Nas outras categorias encontramos aproximadamente um terço dos professores em cada uma das situações (após a graduação, após o mestrado e após o doutorado).

Metade dos bolsistas de produtividade e dos professores da UFMG iniciou sua vida profissional em empresas. Metade dos professores das faculdades privadas e das universidades sem pós iniciou sua vida profissional na instituição onde se encontra atualmente. $16,1 \%$ dos professores das faculdades privadas iniciaram suas vidas profissionais lecionando na educação básica. Esse dado é interessante, pois estamos lidando, aqui, com a área da engenharia e não com licenciatura.

\section{b) Matemática}

O tempo decorrido entre o final da graduação e o início do mestrado é mais elevado para os professores das faculdades privadas (11 anos) e para os professores dos mestrados em educação matemática (6,9 anos), e é menor para as outras categorias (variando de 1,2 a 2,9 anos). Os professores da área de matemática têm uma trajetória profissional um pouco diferente daqueles da engenharia. A porcentagem dos professores que iniciaram sua vida profissional na instituição atual é alta para todas as categorias e é mais alta para os professores das universidades com pós-graduação $(73,9 \%)$, para os bolsistas de 
produtividade $(78,3 \%)$ e para os professores da UFMG $(57,5 \%)$, e mais baixa para os professores das universidades sem pós (34,3\%) e dos mestrados em educação matemática $(44,4 \%)$.

Uma grande parcela dos professores das universidades com pós, dos mestrados em educação matemática, da UFMG e dos bolsistas de produtividades trabaIharam, em seu primeiro emprego, em outra universidade pública. Uma grande parcela dos professores das faculdades privadas e das universidades sem pós (quase a metade de cada categoria) iniciou sua vida profissional lecionando na educação básica. E uma parcela significativa dos professores das universidades sem pós iniciou suas atividades lecionando em faculdades privadas (20\%). Quase $90 \%$ dos professores das faculdades privadas iniciaram sua vida profissional após a graduação. Esse número é também alto para os professores das universidades sem pós (63\%). Nas outras categorias, há uma distribuição diferente, mas, de qualquer forma, há um grande número de professores que iniciaram sua carreira acadêmica depois da graduação. Apenas uma pequena parcela dos professores das faculdades privadas adquire qualificação (mestrado e doutorado), os professores das instituições públicas se qualificam durante a sua trajetória acadêmica, o que nos leva a pensar que essas instituições incentivam e exigem a maior qualificação, seja através de programas específicos, seja através do sistema de recompensas.

\section{c) Filosofia}

$\mathrm{Na}$ área da filosofia, o tempo decorrido entre o final da graduação e o início do mestrado é mais elevado para todas as categorias e semelhante entre elas (entre 5,5 e 6,1 anos, em média), com a diferença dos bolsistas de produtividade, que apresentam um tempo menor (2,4 anos). Uma parcela elevada de professores de todas as categorias, com a única exceção dos professores da UFMG, começou sua carreira acadêmica na instituição atual (em torno de $42 \%$ em todas as categorias, $1 \%$ na UFMG). Uma grande parcela dos professores da UFMG iniciou sua carreira em outra universidade pública (50\%), uma grande parcela em instituições privadas (44\%) e o restante lecionando na educação básica (6\%). Uma parcela elevada de professores das instituições privadas $(19,3 \%)$ e das universidades sem pós $(23,5 \%)$ e das universidades com pós $(25,5 \%)$ iniciou sua vida profissional lecionando na educação básica. Isso não ocorre para os professores da UFMG e para os bolsistas de produtividade. A maioria dos professores das faculdades privadas, das universidades sem pós e com pós e da UFMG iniciou sua carreira acadêmica após a graduação. Entre os bolsistas, há um mesmo número, elevado, que iniciou sua carreira após a graduação e após o mestrado $(44,4 \%)$. Aqui também podemos afirmar que a qualificação do professor 
está relacionada à instituição na qual exerce sua profissão.

\section{d) Psicologia}

Entre os professores de psicologia, o tempo decorrido entre o fim da graduação e o início do mestrado é elevado (em torno da média de 4 anos), mas é mais elevado entre os professores das faculdades privadas ( 6 anos) e os das universidades com pós (5,6 anos). Mais de um terço dos professores de todas as categorias, com exceção daqueles das universidades sem pós, não teve nenhum tipo de emprego anterior à entrada na carreira acadêmica. A maioria dos professores das universidades sem pós (64,3\%) iniciou sua vida profissional lecionando em uma instituição privada. Esse número é também elevado para todas as outras categorias: quase metade dos professores da UFMG e das universidades com pós e $35,7 \%$ dos bolsistas de produtividade.

A área da psicologia é a única dentre as estudadas que possui bolsistas de produtividade que exercem a profissão acadêmica em instituição privada de ensino. Para todas as outras áreas, esses bolsistas pertencem ou à UFMG (a maioria) ou a universidades com pós-graduação. Um número elevado de professores das faculdades privadas $(28,5 \%)$ e das universidades sem pós $(21,4 \%)$ iniciou sua vida profissional trabalhando em uma empresa. E 9,7\% dos professores das faculdades privadas iniciou sua vida profissional lecionando na educação básica.

Para todas as categorias, a maioria dos professores iniciou sua vida acadêmica depois da graduação. Nas faculdades privadas, nenhum iniciou a vida acadêmica após o doutorado.

Os dados anteriores nos permitem deduzir que os professores das universidades sem pós possuem características de trajetórias que se assemelham mais aos professores das faculdades privadas do que às outras categorias. Isso nos leva a pensar nos critérios de recrutamento do corpo docente adotados por essas instituições e no mercado de trabalho acadêmico. A inexistência de pós-graduação e a localização fora de grandes centros tornam essas instituições menos atrativas para os profissionais com melhor qualificação e com um maior capital cultural e social. Um corpo docente socializado em instituições sem tradição de pesquisa não adquire as habilidades e competências adequadas a essa prática e, muito provavelmente, não conseguirão manter os padrões necessários para a implantação de cursos de pós-graduação.

Deduzimos também que a qualificação do professor é realizada dentro da instituição de ensino na qual trabalha. Assim, podemos inferir que as instituições públicas com pós-graduação oferecem melhores condições de qualificação 
de seu corpo docente.

Os professores que estão em instituições e em cargos de maior prestígio apresentam uma trajetória diferenciada, que aponta para uma carreira consciente: um tempo menor entre a graduação e o mestrado, o tipo do primeiro emprego (muito poucos entre eles atuam na educação básica, por exemplo). As diferenças entre áreas existem: na engenharia esses professores do topo da carreira acadêmica, por exemplo, iniciaram sua vida profissional em uma empresa, trabalhando em sua área de formação. Além disso, encontramos um percentual muito maior de homens na engenharia em comparação com as demais disciplinas, principalmente com a psicologia.

\section{As práticas e a lógica da prática}

Levaremos em consideração, dentro da trajetória acadêmica, os seguintes indicadores da prática profissional: o ensino (número de disciplinas diferentes lecionadas na graduação e na pós-graduação, nos últimos dez anos); produtividade (média de publicação nos últimos dez anos); e o número de cargos administrativos ocupados nos últimos dez anos.

\subsection{O ensino}

Nós não conseguimos a carga horária do professor, mas utilizamos o número de disciplinas diferentes lecionadas nos últimos dez anos. A cada nova disciplina é necessário um esforço maior do professor, no sentido de pesquisar a bibliografia e de preparar as suas aulas, o que envolve muita leitura. O senso comum nos leva a pensar que os professores das instituições privadas, sem pós-graduação, por serem horistas e não terem compromissos com a pesquisa e a extensão, fosse aqueles que tivessem um número maior de disciplinas diferentes lecionadas nos últimos dez anos. Mas, para todas as áreas, o que verificamos foi exatamente o oposto: os professores das faculdades privadas lecionam um número inferior de disciplinas diferentes (5,3 disciplinas nos últimos dez anos) do que os outros professores ( 9,4 disciplinas nos últimos dez anos). Os bolsistas de produtividade (11 disciplinas em média nos últimos dez anos) e os professores da UFMG (10 disciplinas em média nos últimos dez anos) apresentam resultados semelhantes e possuem o maior número de disciplinas diferentes lecionados nos últimos dez anos. São exatamente os professores que se envolvem com pesquisa que parecem possuir uma maior facilidade de lecionar disciplinas diferentes. 
Em relação à área de conhecimento, observamos que os professores de cursos que possuem uma prática profissional além da prática acadêmica lecionam um número menor de disciplinas do que os professores de áreas cuja prática é acadêmica.

Na engenharia, a média é de 6,6 disciplinas nos últimos dez anos (variando de 3,8 disciplinas nas universidades sem programas de pós-graduação, 5,2 disciplinas nas instituições privadas, 7,6 disciplinas nas universidades com programas de pós-graduação, 7,5 disciplinas na UFMG e 8,7 disciplinas no grupo de bolsistas de produtividade). Na área de matemática, a média geral é de 9,2 disciplinas lecionadas nos últimos dez anos (6,5 para as instituições privadas, 5,0 para as universidades sem programa de pós-graduação, 10,1 para as universidades com programas de pós-graduação, 11,4 para a UFMG e 11,7 para os bolsistas de produtividade). Na área da filosofia, a média geral é de 8,6 disciplinas nos últimos dez anos (5,1 para as instituições privadas, 7,4 para as universidades sem pósgraduação, 9,0 para as universidades com pós-graduação, 11,2 para a UFMG e 10,2 para os bolsistas de produtividade). Na área da psicologia, a média geral é de 5,8 disciplinas nos últimos dez anos (4,4 para as instituições privadas, 4,6 para as universidades sem pós-graduação, 5,2 para as universidades com pósgraduação, 7,8 para a UFMG e 7,2 para os bolsistas de produtividade).

\subsection{A produtividade}

A produtividade se refere às atividades de pesquisa e às atividades de divulgação do conhecimento produzido dentro das instituições.

\section{a) Engenharia}

Nossos dados nos mostram claramente que a produtividade do professor se relaciona à presença ou ausência de um programa de pós-graduação na área de sua atuação. Mas, mesmo nas universidades com pós-graduação do interior, encontramos $6,9 \%$ de professores que nunca publicaram. Esse número é elevado para as universidades sem pós-graduação (48\%) e maior ainda para as faculdades privadas $(64,4 \%)$.

Em geral, os professores de engenharia publicaram 10,4 artigos em periódicos nos últimos dez anos, 0,97 capítulos de livros, 1,9 livros e 29,4 trabalhos completos publicados em anais de congressos. Os professores bolsistas de produtividade publicaram mais artigos $(17,7)$, mais capítulos de livros $(2,6)$, mais trabalhos completos em anais de congressos $(53,4$ trabalhos por professor nos 
últimos dez anos), seguidos pelos professores de universidades com programas de pós-graduação (17,1 artigos e 30,2 trabalhos publicados em anais) e professores da UFMG (13,6 artigos e 52,7 trabalhos publicados em anais). Os professores das universidades sem pós-graduação apresentam resultado semelhante aos professores das instituições privadas, números muito baixos (1 artigo nos últimos dez anos e 1,63 trabalhos publicados em anais).

Na área da engenharia o meio de publicação é preferencialmente anais de congressos. Em segundo lugar, artigos publicados em periódicos. Livros e capítulos de livros são mais raros.

\section{b) Matemática}

A produtividade na área da matemática é muito menor do que na engenharia. Em geral, os professores da área de matemática publicaram 6,2 artigos em periódicos nos últimos dez anos e 5,8 trabalhos completos em anais de congressos. O número de capítulos de livros e de livros é irrelevante (0,5 para as duas categorias). Os bolsistas de produtividade publicaram mais artigos $(17,5)$, enquanto os professores de mestrado em educação publicaram mais trabalhos completos em anais de congressos (14).

Os professores publicam mais em periódicos e em anais de congressos. Mas, com exceção dos bolsistas de produtividade, a produtividade da área é muito baixa. A relação de produtividade entre as categorias é a mesma da área da engenharia.

\section{c) Filosofia}

A média das publicações na área de filosofia é a seguinte: 8,1 artigos publicados em periódicos nos últimos dez anos, 6,1 capítulos de livros, 2,5 livros e 1,9 trabalhos completos publicados em anais. Os bolsistas de produtividade publicaram mais artigos (14), mais capítulos de livros $(14,8)$, mais livros $(5,3)$, seguidos pelos professores da UFMG (10,3 artigos, 8,8 capítulos de livros, 3,8 livros), pelos professores das universidades com programas de pós-graduação (8,2 artigos, 5,0 capítulos, 2,2 livros), pelos professores das universidades sem pós-graduação (6,1 artigos, 1,3 capítulos, 1,3 livros). A publicação de professores de instituições privadas é irrisória.

A produtividade da área da filosofia também é mais baixa que na engenharia. Aqui há mais publicação de capítulos de livros do que nas outras áreas e menos publicação em anais de congressos. A maior parte da publicação ocorre em 
periódicos. A relação entre as categorias se mantém igual às outras áreas.

\section{d) Psicologia}

Em média, os professores da área de psicologia publicaram 12,8 artigos em periódicos nos últimos dez anos, 5,9 capítulos de livros, 1,5 livros e 6,9 trabalhos completos publicados em anais de congressos. A relação entre as categorias é semelhante à encontrada nas outras áreas. Os bolsistas de produtividade, claro, possuem uma maior produtividade (24,3 artigos em periódicos nos últimos dez anos, 11,6 capítulos de livros, 2,9 livros e 9,9 trabalhos completos publicados em anais de congressos), seguidos pelos professores da UFMG (16,5 artigos, 9,6 capítulos de livros, 2,3 livros e 7,2 trabalhos completos em anais), pelos professores de universidades com pós-graduação (14,8 artigos, 4,8 capítulos de livros, 1,2 livros e 11,3 trabalhos completos em anais). Os professores das universidades sem pós-graduação possuem produtividade semelhante aos professores das instituições privadas e os números são irrisórios.

A produtividade na área da psicologia é menor que na engenharia, mas maior que nas outras duas áreas. A preferência é por artigos em periódicos e por capítulos de livros. A relação entre as categorias é a mesma que nas outras áreas.

Podemos concluir essa sessão com as seguintes afirmações:

a) A produtividade se relaciona com a presença/ausência de programas de pós-graduação stricto sensu (mestrados e doutorados).

b) Quando olhamos as curvas de distribuição da produtividade, observamos que, em todas as categorias e em todas as áreas, há um número pequeno de professores que publicam muito e um número maior de professores que publicam pouco.

c) Cada área possui canais de publicação privilegiados diferentes das outras áreas.

\subsection{Tarefas administrativas e burocráticas}

Utilizamos como índice da quantidade (e do tempo e energias gastos) de tarefas administrativas, o número de cargos ocupados nos últimos dez anos. Vejamos como esse índice se comporta nos diversos cursos. 


\section{a) Engenharia}

Os professores da área de engenharia, em todas as categorias, participam de atividades administrativas, ocupando inclusive cargos de direção de institutos e pró-reitorias. Isso acontece até nas instituições privadas.

A maior porcentagem de professores com cargos administrativos está entre os bolsistas de produtividade (81,6\% ocuparam pelo menos 02 cargos administrativos nos últimos dez anos), seguidos pelos professores da UFMG (61,5\% ocuparam cargos nos últimos dez anos) e pelos professores das universidades com pós-graduação (50\%). Já nas universidades sem pós-graduação (35\%) e nas instituições privadas, $(20,3 \%)$ a porcentagem é bem menor.

\section{b) Matemática}

A porcentagem de professores da área de matemática envolvidos em cargos administrativos é menor em todas as categorias do que na área da engenharia. Os cargos se limitam a coordenadores de curso e chefes de departamentos. Encontramos apenas um professor que foi diretor de unidade.

Também aqui a maior porcentagem de professores envolvidos na administração está com os bolsistas de produtividade (60\% dos professores ocuparam pelo menos dois cargos administrativos nos últimos dez anos), seguidos pelos professores da UFMG (31\%), pelos professores das instituições públicas com pósgraduação $(19,4 \%)$, pelos professores de mestrados em educação matemática $(22,6 \%)$. Também aqui, os professores de universidades sem pós-graduação (16\%) e os das instituições privadas $(6,1 \%)$ são aqueles que menos possuem cargos de administração.

\section{c) Filosofia}

Também os professores da área da filosofia apresentam números mais baixos de professores envolvidos em cargos administrativos. Também aqui eles ocupam preferencialmente chefias de departamento, coordenações de colegiados, coordenação de comitês de pesquisa e coordenação de programas de pós-graduação. Não encontramos professores ocupando outros cargos.

$E$, igualmente, aqui, os professores que mais se envolvem com administração são os bolsistas de produtividade (60\% ocuparam pelo menos dois cargos nos últimos dez anos), seguidos pelos professores da UFMG $(47,1 \%)$ e pelos das universidades com pós-graduação (40\%). As outras categorias apresentam 
poucos professores com cargos administrativos (os professores das universidades sem pós-graduação, $21,2 \%)$, especialmente nas privadas $(5,2 \%)$, por não terem uma estrutura de tomada de decisões coletiva.

d) Psicologia

A área da psicologia apresenta um quadro um pouco diferente: os professores ocupam mais cargos que as duas áreas anteriores, embora menos do que a engenharia. Os professores das universidades com pós-graduação (70\% ocuparam pelo menos dois cargos nos últimos dez anos) são os que apresentam uma maior porcentagem de professores que ocupam cargos administrativos, seguidos dos professores da UFMG $(69,7 \%)$ e dos bolsistas de produtividade (60\%). As outras duas categorias apresentam números bem inferiores (37\% para os professores de universidades sem pós-graduação e 9,1\% para os professores das instituições privadas).

Os cargos ocupados são semelhantes às outras duas áreas: coordenação de curso, coordenação de pós-graduação, chefia de departamento e comitê de pesquisa. Não encontramos em nossa amostra outros tipos de cargos.

\section{Conclusão}

Os dados obtidos a partir dos currículos Lattes nos permitem ir além das entrevistas e pensar que a profissão acadêmica possui uma lógica, mesmo possuindo diferentes perfis de profissão acadêmica, correspondentes a diferentes disciplinas ou profissões e a diferentes departamentos e instituições.

A partir dos dados de nossa pesquisa podemos desenhar uma carreira acadêmica que se diferencia de acordo com o tipo de instituição na qual o professor atua. Observamos que aqueles professores que se dirigem às instituições de maior prestígio e aos cargos de maior prestígio (professores de programas de pós-graduação e bolsistas de produtividade) têm uma carreira mais definida, desde a sua formação: o tempo decorrido entre o término da graduação e o início do mestrado é menor do que dos outros professores. Eles também se formam em instituições de maior prestígio. Não temos dados concretos para afirmar, mas podemos inferir e sugerir que esses professores possuem um capital cultural e um capital social maior do que os outros, já que possuem a informação da trajetória que devem seguir na carreira acadêmica.

Observamos também que o tipo de instituição e o local da instituição têm um efeito na carreira acadêmica. A formação acadêmica é realizada, na maior parte, durante a prática profissional, e não antes, para os professores das 
instituições de maior prestígio. Nas instituições de pós-graduação há um número maior de professores qualificados (com doutorado) do que nas instituições sem pós-graduação, mesmo sendo elas públicas. Assim, as atividades de pesquisa existentes em uma instituição e os cursos de pós-graduação não só guiam o recrutamento de professores mais qualificados, como promovem a qualificação dos professores de seus quadros (lembrando que uma boa parcela dos professores inicia sua carreira nessas instituições antes do doutorado).

Ao contrário do que se imagina normalmente, são os professores das instituições de pesquisa e os bolsistas de produtividade que mais possuem projetos de extensão, atividades administrativas, lecionam um maior número de disciplinas diferentes e, claro, possuem uma maior produtividade. E os professores das instituições sem pós-graduação possuem menos projetos de extensão, menos pesquisas, menos atividades administrativas e lecionam um número bem menor de disciplinas diferentes. Nas instituições privadas, como se sabe, predomina o ensino.

Esses dados nos levam a duas conclusões principais: a primeira, sobre o efeito da instituição sobre a prática profissional; e o segundo sobre a existência de uma carreira acadêmica. Os dados de nossa pesquisa apontam para o efeito da filiação departamental na prática do professor.

Parece existir um modelo de carreira com papéis diferenciados envolvendo a produção do conhecimento para poucos, para uma minoria de pesquisadores e eruditos, e outro papel envolvendo a transmissão do conhecimento à clientela laica, sendo realizado pela maioria que ensina em faculdades e universidades. Sem esse último, como bem nos mostra Freidson (1986), o primeiro não poderia existir: algumas outras fontes de vida, com suas próprias contingências especiais seriam necessárias. Nesse sentido, os dois papéis são interdependentes e interativos. A produção de conhecimento através da pesquisa ou da erudição é uma atividade subsidiária para a maioria dos membros de ambas as profissões (os bolsistas de produtividade lecionam um número maior de disciplinas diferentes, o que mostra o envolvimento com o ensino), realizada no tempo que sobra depois que eles executam o trabalho do qual a sua vida depende. Pesquisa e erudição são ocupações secundárias, não primárias; em termos mais gráficos, segundo Freidson, elas são ocupações parasitas, sendo o ensino a ocupação hospedeira. Assim, não é inapropriado tratar as disciplinas acadêmicas como profissões, já que a atividade fundamental sobre a qual depende sua oportunidade para produzir novas ideias e novos conhecimentos consiste em prestar serviços pessoais de educação superior à clientela leiga. 


\section{Referências bibliográficas}

BLAU, P. The organization of academic work. New Jersey: Transaction Publishers, 1994 (2a ed.).

SCHWARTZMAN, S.; BALBACHEVSKY, E. "A profissão acadêmica no Brasil", in Phillip G. Altbach (ed.), The International Academic Profession: Portraits from 14 Countries. Princeton, NY: Carnegie Foundation for the Advancement of Teaching, 1997.

FREIDSON, E. "Knowledge and the practice of sociology". Sociological Forum, vol. 1 , no. 4, 1986, p. 684-700.

STEINER, J. E. "Diferenciação e classificação das instituições de ensino superior no Brasil", in STEINER, J. E. e MALNIC, G. (orgs) Ensino Superior. Conceito e Dinâmica. São Paulo: Edusp, 2006.

WELCH, A. The Professoriate. Dordrecht: Springer, 2007. 